\title{
Leaching Kinetics of Zinc from Metal Oxide Varistors (MOVs) with Sulfuric Acid
}

\author{
Youngjin Kim and Jaeryeong Lee * \\ Department of Energy \& Resources Engineering, Kangwon National University, Chuncheon 24341, Korea; \\ yjcokr@kangwon.ac.kr \\ * Correspondence: jr-lee@kangwon.ac.kr; Tel.: +82-33-250-6252
}

Academic Editor: Hugo F. Lopez

Received: 22 July 2016; Accepted: 17 August 2016; Published: 19 August 2016

\begin{abstract}
The leaching kinetics of zinc from zinc oxide-based metal oxide varistors (MOVs) was investigated in $\mathrm{H}_{2} \mathrm{SO}_{4}$ at atmospheric pressure. Kinetics experiments were carried out at various agitation speeds, particle sizes, initial $\mathrm{H}_{2} \mathrm{SO}_{4}$ concentrations, and reaction temperatures. It was determined that the leaching rate of zinc was independent of agitation speed above $300 \mathrm{rpm}$ and also independent of particle size below $105 \mu \mathrm{m}$, whereas it dramatically increased with an increasing $\mathrm{H}_{2} \mathrm{SO}_{4}$ concentration. Except for when the $\mathrm{H}_{2} \mathrm{SO}_{4}$ concentration was varied, the $m$-values were almost constant at varying agitation speeds ( $m$-values: $0.554-0.579)$, particle sizes ( $m$-values: $0.507-0.560)$ and reaction temperature ( $m$-values: $0.530-0.560)$ conditions. All of the $m$-values in these experiments were found to be below 0.580 . Therefore, it is proposed that the extraction of zinc is a diffusion-controlled reaction. The leaching kinetics followed the D3 kinetic equation with a rate-controlling diffusion step through the ash layers, and the corresponding apparent activation energy was calculated as $20.7 \mathrm{~kJ} / \mathrm{mol}$ in the temperature range of $313 \mathrm{~K}$ to $353 \mathrm{~K}$.
\end{abstract}

Keywords: leaching kinetics; zinc leaching; metal oxide varistors (MOVs); sulfuric acid

\section{Introduction}

Many researchers have recovered metals from waste printed circuit boards (WPCBs) due to the dramatic increase in the amount of WPCBs. There are many papers reporting on the recovery of high content metals $(\mathrm{Cu}, \mathrm{Al}, \mathrm{Sn})$ or precious metals $(\mathrm{Au}, \mathrm{Ag})$ from WPCBs using physical, chemical, or biological methods, or a combination of these approaches [1-12]. However, these processes are very difficult to perform and are expensive not only for the concentration of minor metals but also for their individual recovery. For these reasons, few studies have focused on the recovery of metals that have low concentrations of electric/electronic components (EECs) due to the diversity of mounted EECs in WPCBs, such as in varistors, condensers, inductors, resistors, diodes, and so on. These EECs consist of various metals, such as zinc, copper, cobalt, and nickel, as well as toxic substances [12]. Among these EECs, metal oxide varistors (MOVs) are widely used in electronic devices. Due to their excellent nonlinear coefficient, low leakage current, and high energy absorption capacity, they have been used as surge absorbers in small current electrical circuits, as well as in transmission lines, for many years $[13,14]$.

MOVs are made by sintering a mixture of zinc oxide with small amounts of other oxides, such as $\mathrm{Bi}_{2} \mathrm{O}, \mathrm{Sb}_{2} \mathrm{O}_{3}, \mathrm{Co}_{2} \mathrm{O}_{3}, \mathrm{Cr}_{2} \mathrm{O}_{3}$, among others [13,14]. Therefore, wasted MOVs, if separated from other types of waste components, could be good starting materials for the recovery of various metals [15]. Gutknecht et al. [15] investigated the leaching of MOVs using four acid solutions, including acetic acid, hydrochloric acid, nitric acid and sulfuric acid. However, this study was not sufficient from an industrial point of view. Similar investigations have been carried out by other research groups [16-18]. However, these studies focused on zinc leaching from electric arc furnace dust (EAF 
dust) or zinc ores. More importantly, except for the Gutknecht study [15], our research group has not found any literature on the recycling of MOVs.

For these reasons, a basic study of the leaching kinetics of the metals from MOVs is important to develop recycling routes for various metals, such as $\mathrm{Zn}, \mathrm{Bi}, \mathrm{Sn}$, and $\mathrm{Co}$, among others.

The main objective of this work is to provide information on the leaching kinetics of zinc from MOVs. Factors influencing zinc extraction, including the agitation speed, particle size, initial $\mathrm{H}_{2} \mathrm{SO}_{4}$ concentration, and reaction temperature, were studied in detail.

\section{Experimental Section}

\subsection{Materials}

The MOVs with dimensions of $15 \mathrm{~mm} \times 25 \mathrm{~mm} \times 4.5 \mathrm{~mm}$ (produced by Thinking Electronic Industrial Co., Ltd., Kaohsiung, Taiwan) were used in the present study. MOVs were ground to a particle size less than $210 \mu \mathrm{m}$ by using a rod mill, and screened into different sized fractions with Tyler sieves. The $-210 \mu \mathrm{m}$ fraction, containing various metals with chemical compositions, as shown in Table 1, was used as the sample for this study. The chemical composition of MOVs was analyzed using inductively coupled plasma spectrometer (ICP) after these were completely dissolved in aqua regia at 383-393 K. These results are summarized in Table 1. The undersized fraction of MOVs contained $70.97 \% \mathrm{Zn}, 2.76 \% \mathrm{Sb}$, and $1.83 \% \mathrm{Bi}$ as major elements. The analysis of the zinc content of different particle sizes and mass fractions of the MOVs, as presented in Table 2, indicates an increase in the percentage of the zinc content with decreasing particle size. Typical X-ray diffraction (XRD) patterns of the MOVs, prepared by rod milling and sieving, are shown in Figure 1. Major intensity peaks correspond to zinc oxide ( $\mathrm{ZnO})$, while minor intensity peaks corresponding to zinc cobalt antimony oxide $\left(\mathrm{Zn}\left(\mathrm{Co}_{1.33} \mathrm{Sb}_{0.67}\right) \mathrm{O}_{4}\right)$ and antimony oxide $\left(\mathrm{Sb}_{4} \mathrm{O}_{6}\right)$ were also detected.

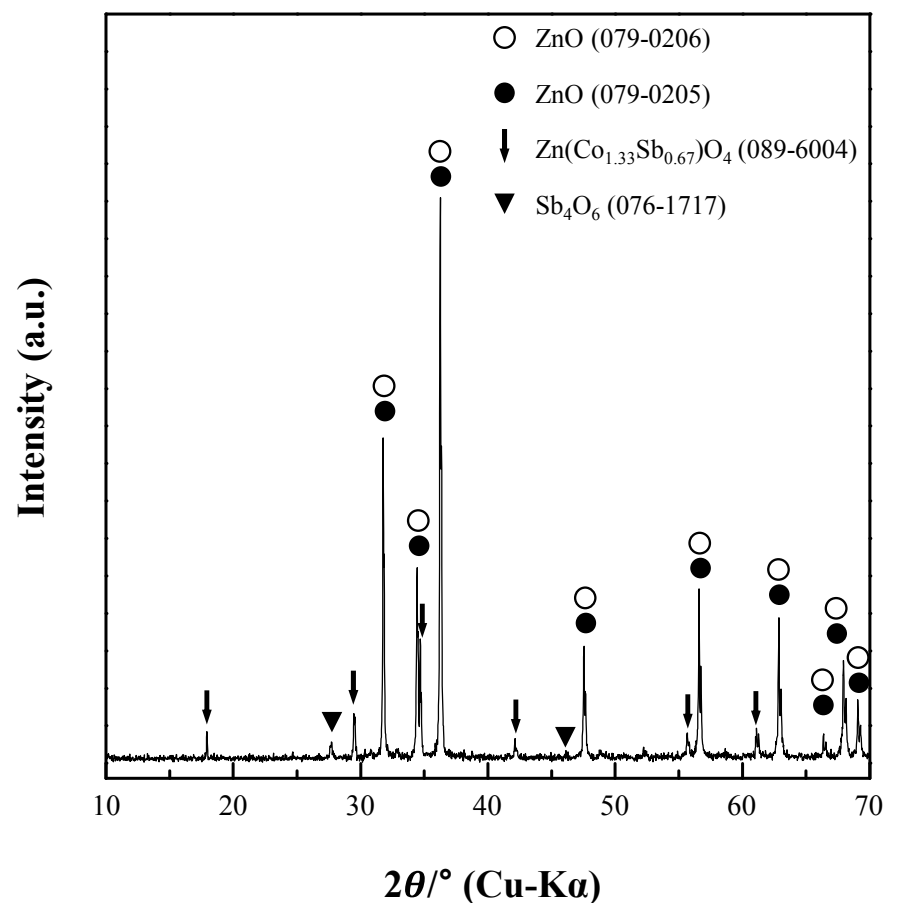

Figure 1. XRD patterns of the MOVs used in this research.

Table 1. Chemical composition of the metal oxide varistors (MOVs) used in this study.

\begin{tabular}{ccccccccccc}
\hline Metal & Zn & Sb & Bi & Co & Al & Ni & Sn & Ag & Ca & Mn \\
\hline wt. $\%$ & 70.97 & 2.76 & 1.83 & 0.77 & 0.58 & 0.44 & 0.43 & 0.41 & 0.33 & 0.33 \\
\hline
\end{tabular}


Table 2. Zn contents in different size fractions of MOVs used in this study.

\begin{tabular}{cccc}
\hline Particle Size & $\mathbf{1 0 5 - 2 1 0} \boldsymbol{\mu m}$ & $\mathbf{5 3 - 1 0 5} \boldsymbol{\mu m}$ & $\mathbf{- 5 3} \boldsymbol{\mu m}$ \\
\hline wt. $\%$ & 63.80 & 72.01 & 72.73 \\
\hline
\end{tabular}

\subsection{Procedures}

The leaching experiments were carried out in a 1-L four-neck thermostatic Pyrex reactor with a heating mantle. The hole at the center of the reactor was fitted with a stirrer, and three side holes were fitted with a reflux condenser, a temperature controller, and a glass cap to collect leach liquor samples. $\mathrm{H}_{2} \mathrm{SO}_{4}(0.5 \mathrm{~L})$ was poured into the reactor and allowed to reach thermal equilibrium. Five grams of the samples was added to the reactor and, in all experiments, the solid/liquid ratio was kept constant at $10 \mathrm{~g} / \mathrm{L}$. Following this, $2 \mathrm{~mL}$ of leach liquor samples were taken periodically (between $0.5 \mathrm{~min}$ and $60 \mathrm{~min}$ ). At selected time intervals, approximately $2 \mathrm{~mL}$ of slurry samples were withdrawn and quickly separated by vacuum filtration. All of the aqueous solutions were prepared using distilled water, and reagent grade $\mathrm{H}_{2} \mathrm{SO}_{4}(95 \%-97 \%$, Merck, Darmstadt, Germany) was used as the solvent.

For quantitative analysis, the chemical digestion method was used for each of the samples. The zinc content was analyzed by using an inductively coupled plasma spectrometer (ICP, Optima 7300 DV, PerkinElmer, Waltham, MA, USA), and the samples were characterized by the high-resolution X-ray diffraction (HRXRD) analysis (X'pert-pro MPD, PANalytical, Almelo, The Netherlands) method.

\section{Results and Discussion}

\subsection{Effect of Agitation Speed}

The effect of the agitation speed on zinc leaching was studied using fine particles of 53 to $105 \mu \mathrm{m}$ and agitation speeds of 100 to $400 \mathrm{rpm}$. Within the series of experiments, the reaction temperature, initial $\mathrm{H}_{2} \mathrm{SO}_{4}$ concentration, and solid-to-liquid ratios were kept constant at $333 \mathrm{~K}, 0.1 \mathrm{M}$, and $10 \mathrm{~g} / \mathrm{L}$, respectively. Figure 2 shows the effect of the agitation speed on the leachability of zinc.

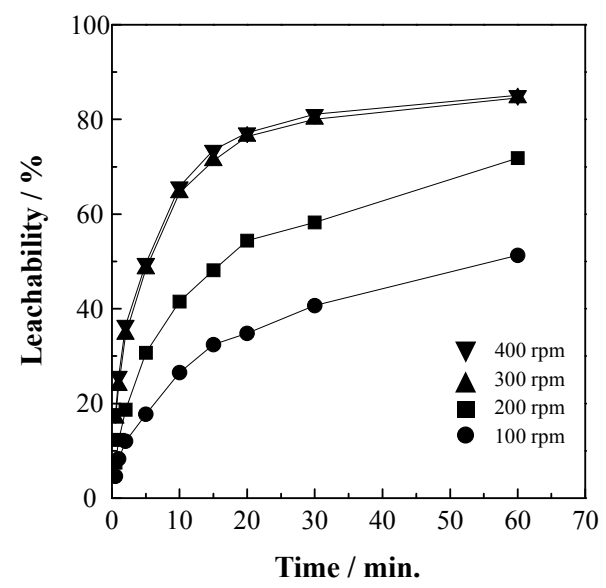

Figure 2. Effect of agitation speed on zinc leaching (initial $\mathrm{H}_{2} \mathrm{SO}_{4}$ concentration: $0.1 \mathrm{M}$; temperature: $333 \mathrm{~K}$; particle size: 53-105 $\mu \mathrm{m}$; pulp density: $10 \mathrm{~g} / \mathrm{L}$ ).

As shown in Figure 2, the leachability of zinc increased with increasing agitation speed and leaching time due to the decreasing thickness of the mass transfer boundary layer on the surface of the MOV particles [19]. However, it was also found that the leachability of zinc remained almost constant over $300 \mathrm{rpm}$. These results indicate that the dissolution process is not controlled by mass transfer through the liquid boundary layer at agitation speeds of or above $300 \mathrm{rpm}$.

An agitation speed of $300 \mathrm{rpm}$ can provide adequate particle suspension. Therefore, all subsequent runs were performed at $300 \mathrm{rpm}[17,18,20]$. 


\subsection{Effect of Particle Size}

A plot of the leachability of zinc against time using different sized fractions (105-210, 53-105, $-53 \mu \mathrm{m}$ ) is presented in Figure 3. In this leaching test, the leaching temperature and initial $\mathrm{H}_{2} \mathrm{SO}_{4}$ concentration were fixed at $333 \mathrm{~K}$ and $0.1 \mathrm{M}$, respectively. The results indicate that the leachability of zinc is almost independent of particle size below $105 \mu \mathrm{m}$. Thus, for further experiments, particles in the size range of 53 to $105 \mu \mathrm{m}$ were chosen to minimize the effect of particle size on leaching [20].

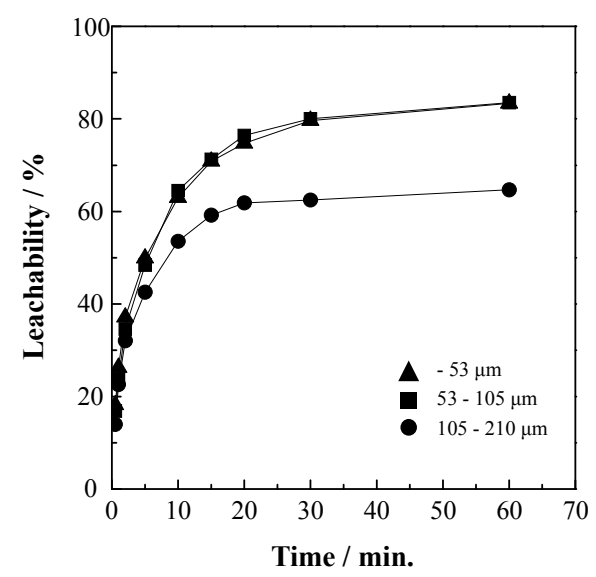

Figure 3. Effect of particle size on zinc leaching (agitation speed: $300 \mathrm{rpm}$; initial $\mathrm{H}_{2} \mathrm{SO}_{4}$ concentration: $0.1 \mathrm{M}$; reaction temperature: $333 \mathrm{~K}$; pulp density: $10 \mathrm{~g} / \mathrm{L}$ ).

\subsection{Effect of $\mathrm{H}_{2} \mathrm{SO}_{4}$ Concentration}

The effect on zinc extraction was studied by varying the initial $\mathrm{H}_{2} \mathrm{SO}_{4}$ concentration from $0.05 \mathrm{M}$ to $1 \mathrm{M}$ while the leaching temperature was kept constant at $333 \mathrm{~K}$. The results are shown Figure 4 . The leachability of zinc increased with the increasing initial $\mathrm{H}_{2} \mathrm{SO}_{4}$ concentration and zinc leaching was typically found to be fast in the initial period up to $10 \mathrm{~min}$, but slowed to a lower rate with further increases in leaching time. It is obvious that the initial $\mathrm{H}_{2} \mathrm{SO}_{4}$ concentration had a pronounced effect on the extraction of zinc.

After $60 \mathrm{~min}$, the leaching ratio reached $100 \%$ in the $\mathrm{H}_{2} \mathrm{SO}_{4}$ concentration range of 0.5 to $1 \mathrm{M}$, whereas the leaching rate was $83.5 \%$ at a $\mathrm{H}_{2} \mathrm{SO}_{4}$ concentration of $0.1 \mathrm{M}$. The effect of $\mathrm{H}_{2} \mathrm{SO}_{4}$ concentration found in these investigations agrees well with the results of other investigators $[15,16,18]$. If all of the zinc in the MOVs is leached, the total zinc concentration will be $0.11 \mathrm{M}$ in the leaching solution because the mole ratio of $\mathrm{H}_{2} \mathrm{SO}_{4}$ to zinc ions is 1 . The experimental results are almost consistent with the fundamental analysis [21].

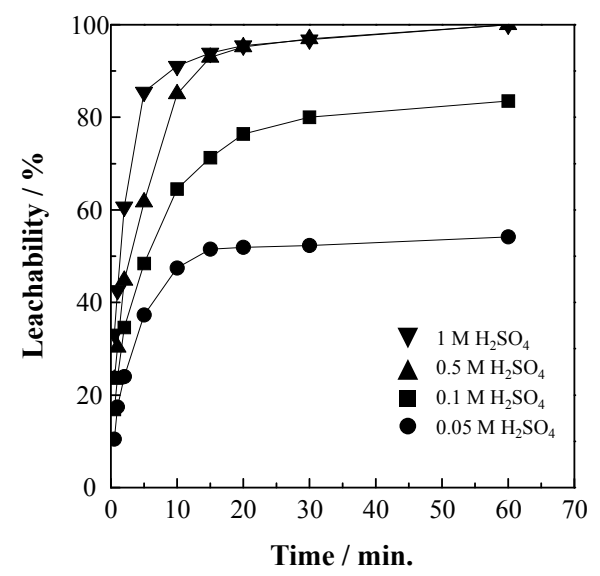

Figure 4. Effect of initial $\mathrm{H}_{2} \mathrm{SO}_{4}$ concentration on zinc leaching (agitation speed: $300 \mathrm{rpm}$; reaction temperature: $333 \mathrm{~K}$; particle size: 53-105 $\mu \mathrm{m}$; pulp density: $10 \mathrm{~g} / \mathrm{L}$ ). 


\subsection{Effect of Reaction Temperature}

The Figure 5 shows the extent of zinc leaching at different reaction temperatures between $313 \mathrm{~K}$ and $353 \mathrm{~K}$ while all of the other parameters were kept constant. The results show that the reaction temperatures do not have a noticeable effect on the zinc extraction. The leachability of zinc initially rose very sharply over approximately $15 \mathrm{~min}$. After $15 \mathrm{~min}$ of treatment, the leachability of zinc increased slowly with an increase in reaction time. The molecular collisions, mass transfer co-efficient, and reaction constant are improved with increasing temperature [19]. However, when the reaction temperature increased from $313 \mathrm{~K}$ to $353 \mathrm{~K}$, the leachability of zinc increased from $80.48 \%$ to $86.8 \%$ after $60 \mathrm{~min}$ in $0.1 \mathrm{M} \mathrm{H}_{2} \mathrm{SO}_{4}$. This weak temperature dependence indicates that the dissolution process does not seem to be controlled by a chemical reaction [22].

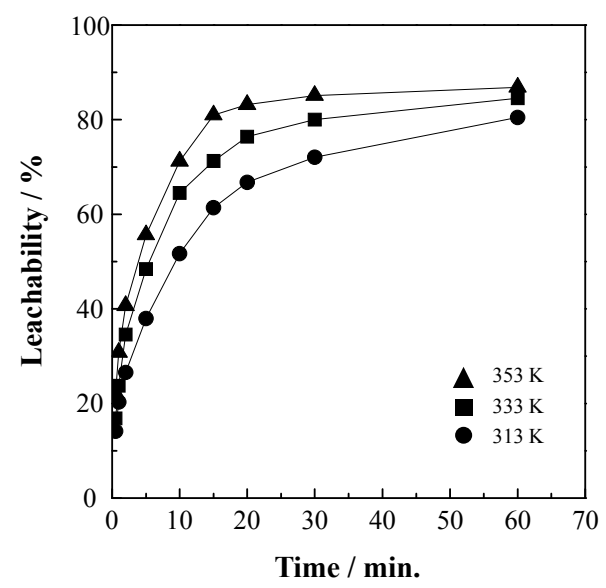

Figure 5. Effect of leaching temperature on zinc leaching (initial $\mathrm{H}_{2} \mathrm{SO}_{4}$ concentration: $0.1 \mathrm{M}$; agitation speed: 300 rpm; particle size: 53-105 $\mu$ m; pulp density: $10 \mathrm{~g} / \mathrm{L})$.

\subsection{Kinetic Analysis}

The leaching process of zinc oxide in a sulfuric acid solution is described by the following chemical reaction [16]:

$$
\mathrm{ZnO}+\mathrm{H}_{2} \mathrm{SO}_{4} \rightarrow \mathrm{ZnSO}_{4}+\mathrm{H}_{2} \mathrm{O}
$$

On the basis of the above reaction, the effects of the temperature, agitation speed, initial $\mathrm{H}_{2} \mathrm{SO}_{4}$ concentration, and particle size on the kinetics of zinc extraction in a sulfuric acid solution are analyzed below. Hancock and Sharp [23] inferred the reaction mechanism through $m$-values, as per the following equation. This method was reported by Sharp et al. [24] and Hancock and Sharp [23]. Baik et al. [25] also used this equation to describe the dissolution of tungsten in $\mathrm{NaOH}$ solution.

$$
-\ln [\ln (1-a)]=\ln k+m \ln t
$$

where $a=$ Fraction of reaction, $k=$ rate constant, $t=$ reaction time.

Kinetic equations for different reaction mechanisms and $m$-values are presented in Table 3. The $m$-values of diffusion-controlled reactions are in the range of 0.54 to 0.62 , while reaction-controlled reactions show an $m$-value of approximately 1.0 [23].

The data presented in Figures 2-5 are plotted according to Equation (2) in Figure 6a-d, respectively. The $m$-values were determined from the straight lines plotted in Figure $6 \mathrm{a}-\mathrm{d}$.

Figure $6 \mathrm{c}$ shows that the $m$-values increased with an increasing initial $\mathrm{H}_{2} \mathrm{SO}_{4}$ concentration from 0.578 to 0.689 . These results suggest that the diffusion mechanism changes with the initial $\mathrm{H}_{2} \mathrm{SO}_{4}$ concentration [25]. However, the $m$-values were almost constant under variable agitation speed ( $m$-values: $0.554-0.579)$, particle size ( $m$-values: $0.507-0.560)$ and reaction temperature ( $m$-values: 
$0.530-0.560)$ conditions. Further, all of the $m$-values in these experiments were below 0.70 , indicating that the mechanisms for all of these reactions may be diffusion-controlled.

Table 3. Reaction mechanisms and equations with changing $m$-values.

\begin{tabular}{cccc}
\hline Notation & Reaction Mechanism & Equation & $m$ \\
\hline D1 & Diffusion & $a^{2}=k t$ & 0.62 \\
D2 & Diffusion & $(1-a) \ln (1-a)+a=k t$ & 0.57 \\
D3 & Diffusion & {$\left[1-(1-a)^{1 / 3}\right]^{2}=k t$} & 0.54 \\
D4 & Diffusion & $1-2 a / 3-(1-a)^{2 / 3}=k t$ & 0.57 \\
\hline F0 & Zero order & $a=k t$ & 1.24 \\
F1 & First order reaction & $-\ln (1-a)=k t$ & 1.00 \\
R2 & Interface reaction (contracting area) & $1-(1-a)^{1 / 2}=k t$ & 1.11 \\
R3 & Interface reaction (contracting volume) & $1-(1-a)^{1 / 3}=k t$ & 1.07 \\
A2 & Nucleation and growth & {$[-\ln (1-a)]^{1 / 2}=k t$} & 2.0 \\
A3 & Nucleation and growth & {$[-\ln (1-a)]^{1 / 3}=k t$} & 3.0 \\
\hline
\end{tabular}
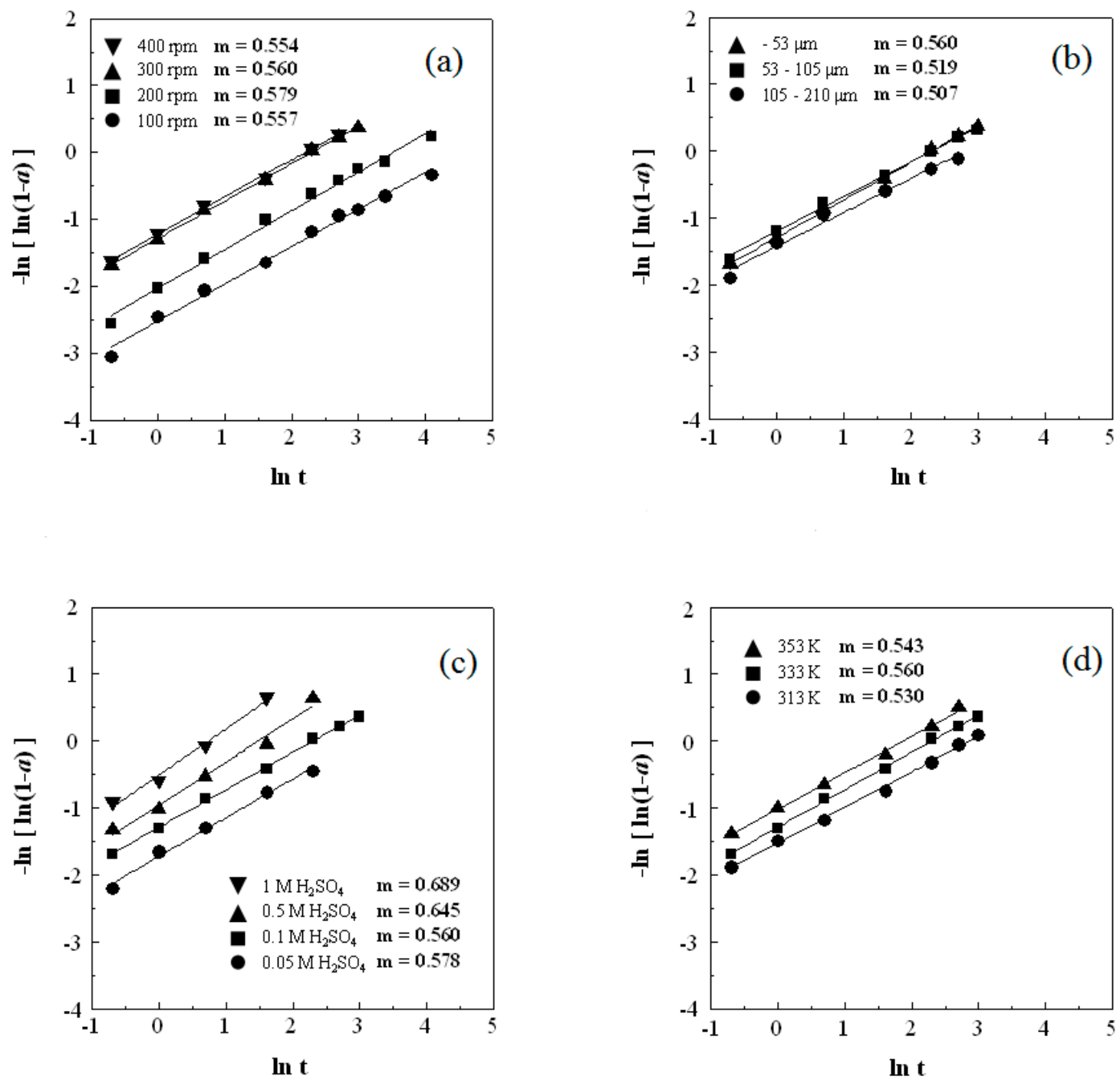

Figure 6. $-\ln [\ln (1-a)]$ vs. $\ln t$ plot for estimating the mechanism of zinc leaching in a $\mathrm{H}_{2} \mathrm{SO}_{4}$ solution. (a) Plot of the results from Figure 2 according to Equation (2); (b) plot of the results from Figure 3 according to Equation (2); (c) plot of the results from Figure 4 according to Equation (2); (d) plot of the results from Figure 5 according to Equation (2). 
To investigate the relation between $m$-values and correlation coefficients $\left(R^{2}\right)$, zinc extraction at varying agitation speeds, initial $\mathrm{H}_{2} \mathrm{SO}_{4}$ concentrations, particle sizes, and temperatures were analyzed according to kinetic equations D1, D2, D3, and D4, respectively, which are shown in Table 3. These expressions were plotted with respect to the reaction time, and the dependence of these diffusion models on the kinetic data was evaluated from $R^{2}$. The plots of each kinetic equation, that is, D1, D2, D3, and D4, versus reaction time under various conditions are shown in Figures 7-10, respectively.
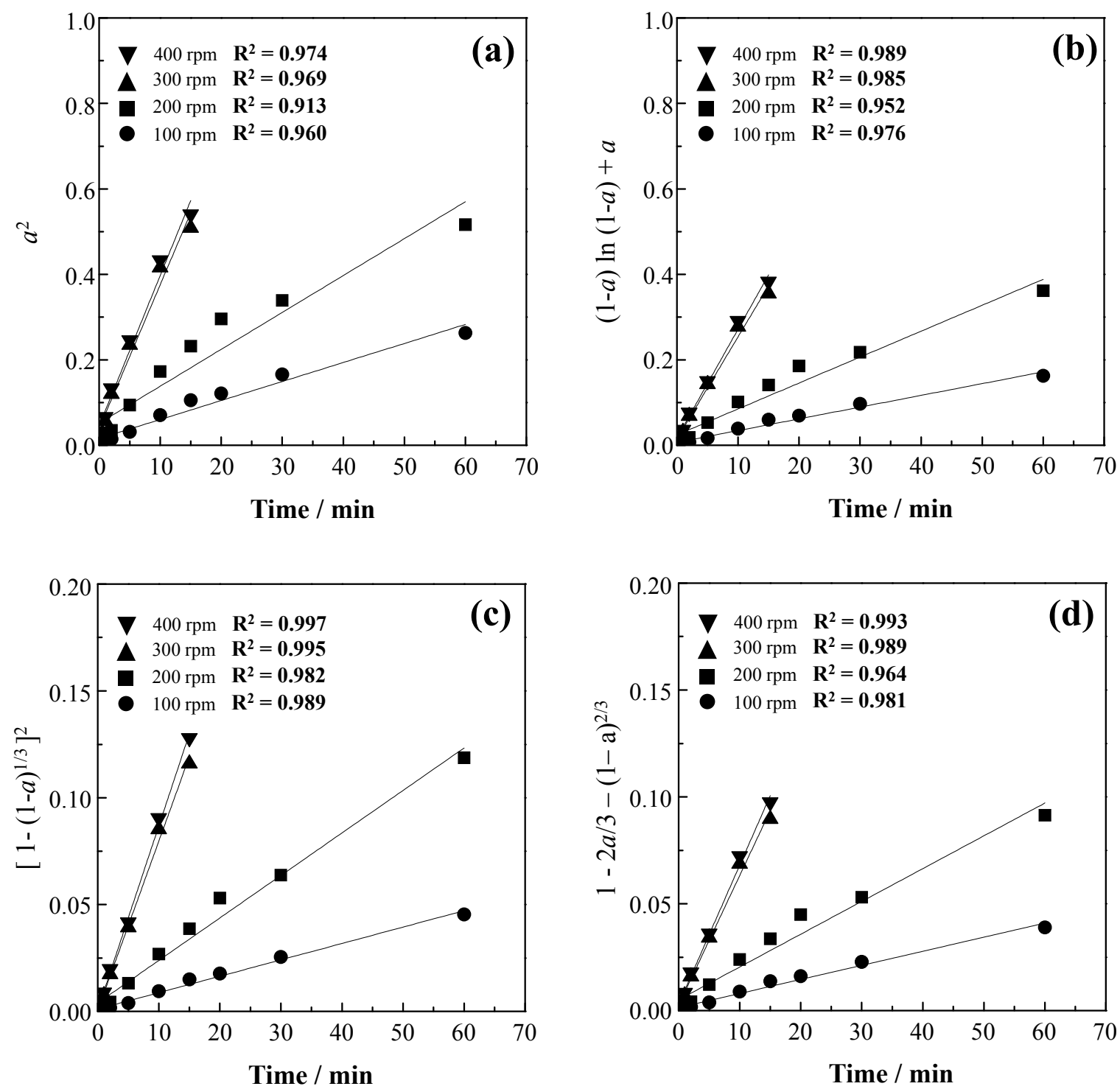

Figure 7. Plots of the diffusion equations vs. time for different agitation speeds according to Figure 2. (a) Plot of the results from Figure 2 according to Equation D1; (b) plot of the results from Figure 2 according to Equation D2; (c) plot of the results from Figure 2 according to Equation D3; (d) plot of the results from Figure 2 according to Equation D4. 

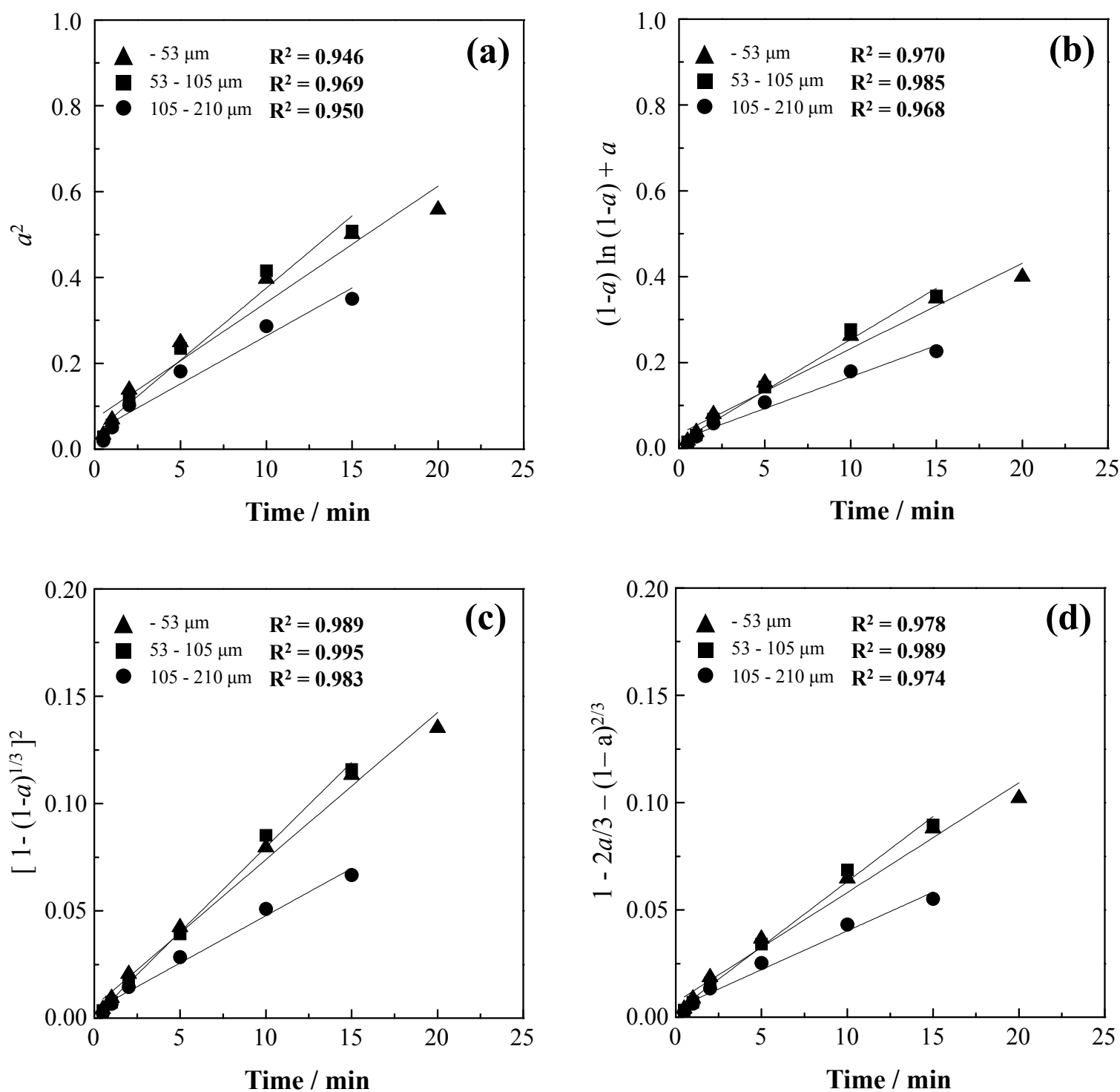

Figure 8. Plots of the diffusion equations vs. time for different particle sizes according to Figure 3. (a) Plot of the results from Figure 3 according to Equation D1; (b) plot of the results from Figure 3 according to Equation D2; (c) plot of the results from Figure 3 according to Equation D3; (d) plot of the results from Figure 3 according to Equation D4. 

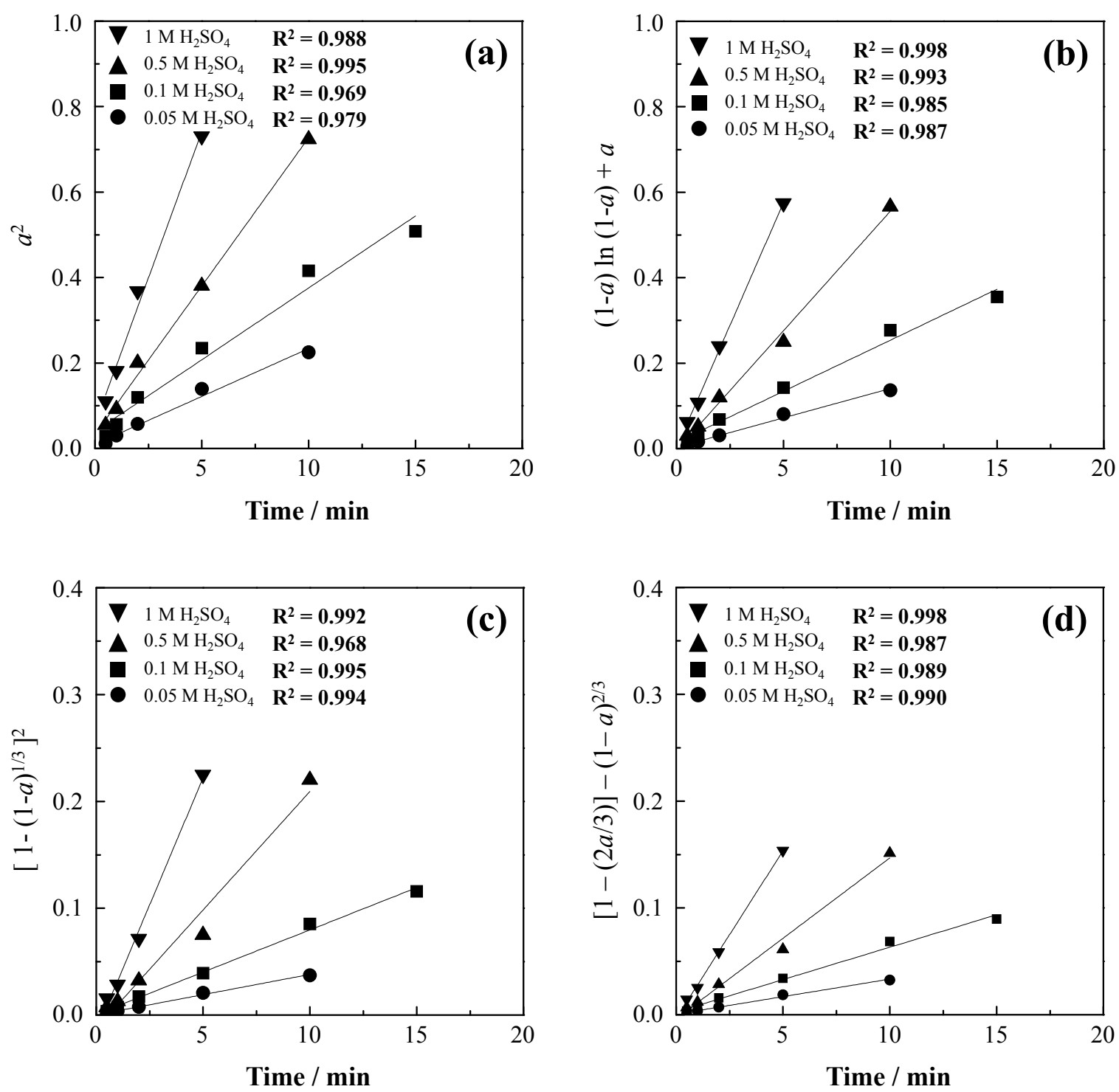

Figure 9. Plots of the diffusion equations vs. time for different initial $\mathrm{H}_{2} \mathrm{SO}_{4}$ concentrations according to Figure 4. (a) Plot of the results from Figure 4 according to Equation D1; (b) plot of the results from Figure 4 according to Equation D2; (c) plot of the results from Figure 4 according to Equation D3; (d) plot of the results from Figure 4 according to Equation D4. 

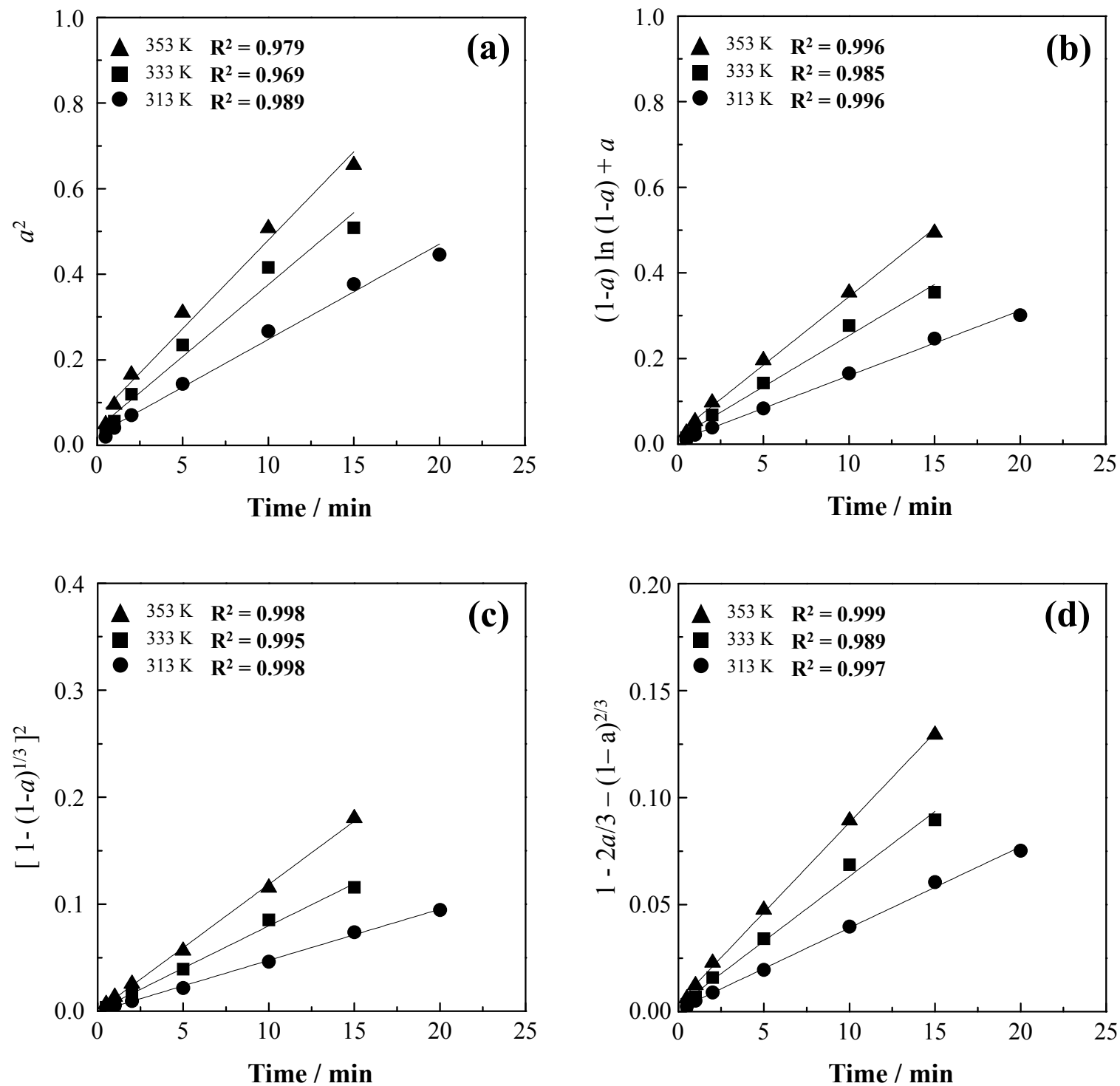

Figure 10. Plots of the diffusion equations vs. time for different temperatures according to Figure 5. (a) Plot of the results from Figure 5 according to Equation D1; (b) plot of the results from Figure 5 according to Equation D2; (c) plot of the results from Figure 5 according to Equation D3; (d) plot of the results from Figure 5 according to Equation D4.

The plots of D1, D2, D3, and D4 versus reaction time at different $\mathrm{H}_{2} \mathrm{SO}_{4}$ concentrations show that $\mathrm{D} 1$ versus reaction time has a good linear relation at $\mathrm{H}_{2} \mathrm{SO}_{4}$ concentrations of $0.5 \mathrm{M}$ and $1 \mathrm{M}$ ( $m$-values: 0.645 and 0.689 , respectively) (Figure 9a). However, the leaching data for $0.05 \mathrm{M}$ and $0.1 \mathrm{M}$ $\mathrm{H}_{2} \mathrm{SO}_{4}$ ( $m$-value: 0.578 and 0.560 , respectively) did not fit well to D1 versus reaction time, as shown in Figure 9a.

Generally, the $R^{2}$ values for Equations D2 and D4 versus reaction time are similar (Figure 7b,d, Figure $8 b, d$, Figure $9 b, d$ and Figure 10b,d), because Equations D2 and D4 have the same $m$-values. In addition, D3 provided a better fit for the kinetic data compared to Equations D1, D2, and D4. On the other hand, Figures 7-10 had smaller $R^{2}$ values for equation D1 versus reaction time those of D2, D3, and $\mathrm{D} 4$ versus reaction time for the case of zinc leaching. This may be because the $m$-values that were calculated using D2, D3, and D4 are in the range of 0.507 to 0.579 , which is close to the $m$-values determined by D2, D3, and D4, as shown in Table 3. 
These results indicate that D2 and D4 provide better fits to the kinetic data than D1. However, the model provided by D3 showed the best fit in all of the experiments. Therefore, this model was chosen to describe the zinc extraction from MOVs during $\mathrm{H}_{2} \mathrm{SO}_{4}$ leaching.

The Arrhenius plot constructed with the rate constant value, $k$, calculated from the data is presented in Figure 10c. The activation energy of zinc leaching by $0.1 \mathrm{M} \mathrm{H}_{2} \mathrm{SO}_{4}$ is $20.7 \mathrm{~kJ} / \mathrm{mol}$ is in the temperature range of $313 \mathrm{~K}$ to $353 \mathrm{~K}$ (Figure 11).

Depending on the activation energy value, the heterogeneous reaction mechanism can be diffusion controlled or chemical reaction controlled. Activation energy values lower than $20 \mathrm{~kJ} / \mathrm{mol}$ usually indicate a diffusion-controlled process, whereas the activation energy of chemical reaction-controlled processes is approximately 50 to $100 \mathrm{~kJ} / \mathrm{mol}[16,17]$. The activation energy value obtained in this study for $\mathrm{Zn}$ leaching is close to $20 \mathrm{~kJ} / \mathrm{mol}$, suggesting a diffusion-controlled process. This confirms that the leaching mechanism is controlled by ash layer diffusion.

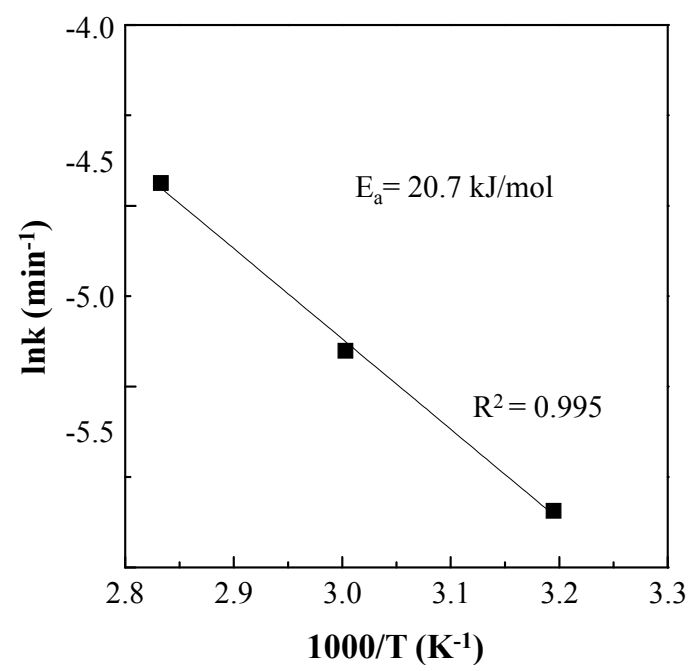

Figure 11. Arrhenius plot of the apparent rate constant.

\section{Conclusions}

The leaching kinetics of zinc from zinc oxide based metal oxide varistors (MOVs) were investigated as a function of the $\mathrm{H}_{2} \mathrm{SO}_{4}$ concentration, reaction time, agitation speed, and temperature. It was found that an agitation speed above $300 \mathrm{rpm}$ was sufficient to eliminate the effect of this variable on the leaching rate and that the extent of zinc extraction increased with the $\mathrm{H}_{2} \mathrm{SO}_{4}$ concentration.

In the plots of $-\ln [\ln (1-a)]$ versus $\ln t$, the $m$-values increased with increasing initial $\mathrm{H}_{2} \mathrm{SO}_{4}$ concentrations, from 0.578 to 0.689 . These results suggest that the diffusion mechanism changes with the $\mathrm{H}_{2} \mathrm{SO}_{4}$ concentration. Except when the $\mathrm{H}_{2} \mathrm{SO}_{4}$ concentration was used as the varying condition, the $m$-values remained almost constant at varying agitation speeds ( $m$-values: $0.554-0.579)$, particle sizes ( $m$-values: $0.507-0.560)$, and reaction temperatures ( $m$-values: $0.530-0.560)$. It is reasonable to conclude that the extraction of zinc seems to be a diffusion-controlled process because all of the $m$-values in these experiments were below 0.70 .

The experimental data agreed quite well with the model described by the D3 kinetic equation:

$$
\left[1-(1-a)^{1 / 3}\right]^{2}=k t
$$

The results of the leaching kinetics experiments show that the zinc leaching process is controlled by ash layer diffusion with an activation energy of $20.7 \mathrm{~kJ} / \mathrm{mol}$.

Acknowledgments: This work was supported by the Korea Institute of Energy Technology Evaluation and Planning (KETEP) and the Ministry of Trade, Industry \& Energy (MOTIE) of the Republic of Korea (No. 20165010100810). 
Author Contributions: Jaeryeong Lee and Youngjin Kim conceived and designed the experiments; Youngjin Kim performed the Leaching experiments and analyzed the ICP data; Youngjin Kim wrote the paper; Jaeryeong Lee modified the paper before submission.

Conflicts of Interest: The authors declare no conflict of interest.

\section{References}

1. Nakamura, T. E-scrap recycling system and technologies in Japan. Geosyst. Eng. 2014, 17, 104-112. [CrossRef]

2. Lee, D.J.; Yoo, C.S. Predicting a promising fusion technology in geoscience and mineral resources engineering using Korean patent data. Geosyst. Eng. 2014, 17, 34-42. [CrossRef]

3. Jeon, S.H.; Park, I.H.; Yoo, K.K.; Ryu, H.J. The effects of temperature and agitation speed on the leaching behaviors of tin and bismuth from spent lead free solder in nitric acid leach solution. Geosyst. Eng. 2015, 18, 213-218. [CrossRef]

4. Oishi, T.; Koyama, K.; Alam, S.; Tanaka, M.; Lee, J.C. Recovery of high purity copper cathode from printed circuit boards using ammoniacal sulfate or chloride solutions. Hydrometallurgy 2007, 89, 82-88. [CrossRef]

5. Han, K.N.; Kellar, J.J.; Cross, W.M.; Safarzadeh, S. Opportunities and challenges for treating rare-earth elements. Geosyst. Eng. 2014, 17, 178-194. [CrossRef]

6. Mecucci, A.; Scott, K. Leaching and electrochemical recovery of copper, lead and tin from scrap printed circuit boards. J. Chem. Technol. Biot. 2002, 77, 449-457. [CrossRef]

7. Veit, H.M.; Diehl, T.R.; Salami, A.P.; Rodrigues, J.D.S.; Bernardes, A.M.; Tenório, J.A.S. Utilization of magnetic and electrostatic separation in the recycling of printed circuit boards scrap. Waste. Manag. 2005, 25, 67-74. [CrossRef] [PubMed]

8. Ganji, S.M.S.A.; Shafaei, S.Z.; Goudarzi, N.; Azizi, A. Investigating the best mixture extraction systems in the separation of rare earth elements from nitric acid solution using Cyanex272, D2EHPA, and 8-Hydroxyquinoline. Geosyst. Eng. 2016, 19, 32-38. [CrossRef]

9. Eswaraiah, C.; Kavitha, T.; Vidyasagar, S.; Narayanan, S.S. Classification of metals and plastics from printed circuit boards (PCB) using air classifier. Chem. Eng. Process. Process Intensif. 2008, 47, 565-576. [CrossRef]

10. Cui, J.; Forssberg, E. Mechanical recycling of waste electric and electronic equipment: A review. J. Hazard. Mater. 2003, 99, 243-263. [CrossRef]

11. Li, J.; Lu, H.; Guo, J.; Xu, Z.; Zhou, Y. Recycle technology for recovering resources and products from waste printed circuit boards. Environ. Sci. Technol. 2007, 41, 1995-2000. [CrossRef] [PubMed]

12. Lee, J.R.; Kim, Y.J.; Lee, J.C. Disassembly and physical separation of electric/electronic components layered in printed circuit boards (PCB). J. Hazard. Mater. 2012, 241, 387-394. [CrossRef] [PubMed]

13. Levinson, L.M.; Philipp, H.R. Zinc oxide varistors-A review. Am. Ceram. Soc. Bull. 1986, 65, 639-646.

14. Li, Y.; Li, G.; Yin, Q. Preparation of $\mathrm{ZnO}$ varistors by solution nano-coating technique. Mater. Sci. Eng. $B$ 2006, 130, 264-268. [CrossRef]

15. Gutknecht, T.; Gustafsson, A.; Forsgren, C.; Ekberg, C.; Steenari, B.M. Investigations into Recycling Zinc from Used Metal Oxide Varistors via $\mathrm{pH}$ Selective Leaching: Characterization, Leaching, and Residue Analysis. Sci. World. J. 2015. [CrossRef] [PubMed]

16. Yoshida, T. Leaching of zinc oxide in acidic solution. Mater. Trans. 2003, 44, 2489-2493. [CrossRef]

17. Erdem, M.; Yurten, M. Kinetics of $\mathrm{Pb}$ and $\mathrm{Zn}$ leaching from zinc plant residue by sodium hydroxide. J. Min. Metall. Sect. B Metall. 2015, 51, 89-95. [CrossRef]

18. Souza, A.D.; Pina, P.S.; Lima, E.V.O.; da Silva, C.A.; Leão, V.A. Kinetics of sulphuric acid leaching of a zinc silicate calcine. Hydrometallurgy 2007, 89, 337-345. [CrossRef]

19. Liao, Y.; Zhou, J.; Huang, F.; Wang, Y. Leaching kinetics of calcification roasting calcinate from multimetallic sulfide copper concentrate containing high content of lead and iron. Sep. Purif. Technol. 2015, 149, 190-196. [CrossRef]

20. Kim, E.Y.; Lee, J.C.; Kim, B.S.; Kim, M.S.; Jeong, J.K. Leaching behavior of nickel from waste multi-layer ceramic capacitors. Hydrometallurgy 2007, 86, 89-95. [CrossRef]

21. Rao, S.; Yang, T.; Zhang, D.; Liu, W.; Chen, L.; Hao, Z.; Xiao, Q.; Wen, J. Leaching of low grade zinc oxide ores in $\mathrm{NH}_{4} \mathrm{Cl}-\mathrm{NH}_{3}$ solutions with nitrilotriacetic acid as complexing agents. Hydrometallurgy 2015, 158, 101-106. [CrossRef] 
22. Levenspiel, O. Chemical Reaction Engineering, 3rd ed.; John Wiley \& Sons Int.: New York, NY, USA, 1999; pp. 566-586.

23. Hancock, J.D.; Sharp, J.H. Method of Comparing Solid-State Kinetic Data and Its Application to the Decomposition of Kaolinite, Brucite, and $\mathrm{BaCO}_{3}$. J. Am. Ceram. Soc. 1972, 55, 74-77. [CrossRef]

24. Sharp, J.H.; Brindley, G.W.; Achar, B.N.N. Numerical data for some commonly used solid stat reaction equations. J. Am. Ceram. Soc. 1966, 49, 379-382. [CrossRef]

25. Baik, S.W.; Shibayama, A.; Murata, K.; Fujita, T. The effect of underwater explosion on the kinetics of alkaline leaching of roasted tungsten carbide scraps for recycling. Int. J. Soc. Mater. Eng. Resour. 2004, 12, 55-59. [CrossRef] article distributed under the terms and conditions of the Creative Commons Attribution (CC-BY) license (http:/ / creativecommons.org/licenses/by/4.0/). 